\title{
A LICHEN-PLANUS-LIKE ERUPTION OCCURRING DURING THE COURSE OF CHLOROQUINE ADMINISTRATION ${ }^{1}$
}

\author{
BY BRANCH CRAIGE, JR.,2 C. MERRILL WHORTON,2 RALPH JONES, JR.,2 \\ THEODORE N. PULLMAN,2 ALF S. ALVING, LILLIAN \\ EICHELBERGER, AND STEPHEN ROTHMAN
}

(From the Malarial Research Unit and the Dermatology Section, Department of Medicine, University of Chicago)

(Received for publication March 12, 1947)

During the course of studies of the chronic toxicity of chloroquine $(\mathrm{SN}-7618)$ in a group of 30 individuals, two exhibited lichen-planus-like eruptions. Since similar lesions have been described following quinacrine administration, detailed protocols of these two cases are herewith presented.

Chloroquine, [7-chloro-4-(4-diethylamino-1methylbutylamino) quinoline], an antimalarial drug superior as a suppressive and therapeutic agent to both quinacrine (atabrine) and quinine $(1,2,3)$, was administered to 30 inmate volunteers at the Illinois State Penitentiary at Stateville, Illinois, for one year in dosages in excess of that required for suppression (1) in order to test the chronic toxicity of the drug (4). ${ }^{8}$

Before medication was started, detailed histories and physical examinations were recorded; and clinical laboratory studies including tests of renal and hepatic function, blood counts, and electrocardiograms were done. During the observation period, the patients were periodically examined,

\footnotetext{
1 This investigation was carried out under a contract, recommended by the Committee on Medical Research, between the Office of Scientific Research and Development and the University of Chicago. The work was planned in cooperation with the Panel on Clinical Testing of Antimalarials of the Board for Coordination of Malarial Studies. This work was further aided by the participation of Army Medical Officers assigned to the project by the Surgeon General, U. S. Army.

The authors express their thanks to the Malaria Study Section of the National Institute of Health for editorial assistance and for arrangements in regard to the publication of this paper. They are also grateful to the Abbott Laboratories, E. I. du Pont de Nemours and Company, Inc., E. R. Squibb and Sons, Eli Lilly and Company, Sharp and Dohme, Inc., and Wyeth, Inc., for contributing toward the publication costs.

2 Captain, M.C., A.U.S.

3 The investigations reported in this paper would not have been possible except for the enthusiastic cooperation of the inmates and the administrative staff of Stateville Penitentiary.
}

weighed, and interviewed and the laboratory tests were repeated.

Of 30 individuals, two developed cutaneous eruptions which resembled lichen planus. Drug administration in both individuals, as in the other members of the group, consisted of a full year of weekly oral doses of 0.5 gram of chloroquine. ${ }^{4}$ The concentration of chloroquine in the plasma reached a weekly peak of between 150 and 250 gamma per liter; and the weekly low level, taken just prior to the succeeding dose, ranged between 20 and 40 gamma per liter.

\section{CASE REPORTS}

Case 1: A 21-year-old otherwise healthy Negro male had had intermittently for several years dry circumscribed neurodermatitis on the nape of the neck. During the first eight months of the study, his only noteworthy symptoms were occasional headaches after taking chloroquine and occasional difficulty in rapid visual accommodation.

In the eighth month of treatment there appeared on the trunk, a faint macular rash which suggested tinea versicolor, but no fungi were found in scrapings on direct microscopic examination. In the eleventh month there was more pronounced scaling of the lesions. At that time the eruption consisted of brown, sharply demarcated macules with branny scales, over the shoulders and trunk, mainly on the back. Mild pruritus was present. The condition somewhat resembled both seborrheic dermatitis and pityriasis rosea. The following month (four months after its first appearance and in the twelfth month of chloroquine administration) the rash spread and became papular and infiltrated.

It then occupied the upper extremities, with a predilection for the flexor surfaces (Figure 1). There were scattered lesions on the medial aspects of the thighs and on the trunk, but none above the shoulders nor on the buccal mucous membranes or genitalia. The lesions varied in size from a few millimeters to several centimeters in diameter. The smaller lesions consisted of reddish violaceous papules with a smooth and slightly shiny surface. The larger lesions were annular and superficial, the center being depressed and paler than the periphery

4 Dosage is expressed in terms of base rather than salt. 


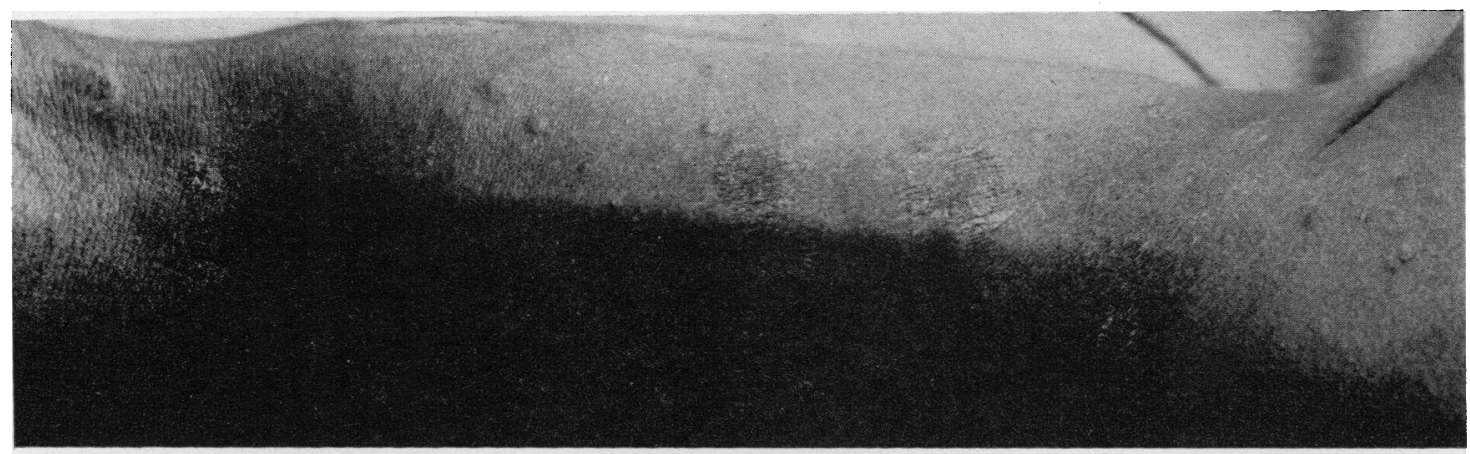

Fig. 1. Cutaneous Eruption during Chronic Chloroquine Administration, Case 1

The lesions scattered from shoulder to antecubital fossa vary from individual papules to large macules. The wrinkling of the central surface of the macules and the peripheral papular elevation are well shown.

which consisted of a ring of confluent, shiny, brownishred or violaceous-red, infiltrated papules. Fine adherent scaling was present on the edges of some macules. None of the lesions was polygonal and no Wickham's striae were noted. The patient felt perfectly well during the period of the cutaneous eruption. There was no other evidence of systemic disease or drug intoxication.

The lesions began to subside within three weeks after

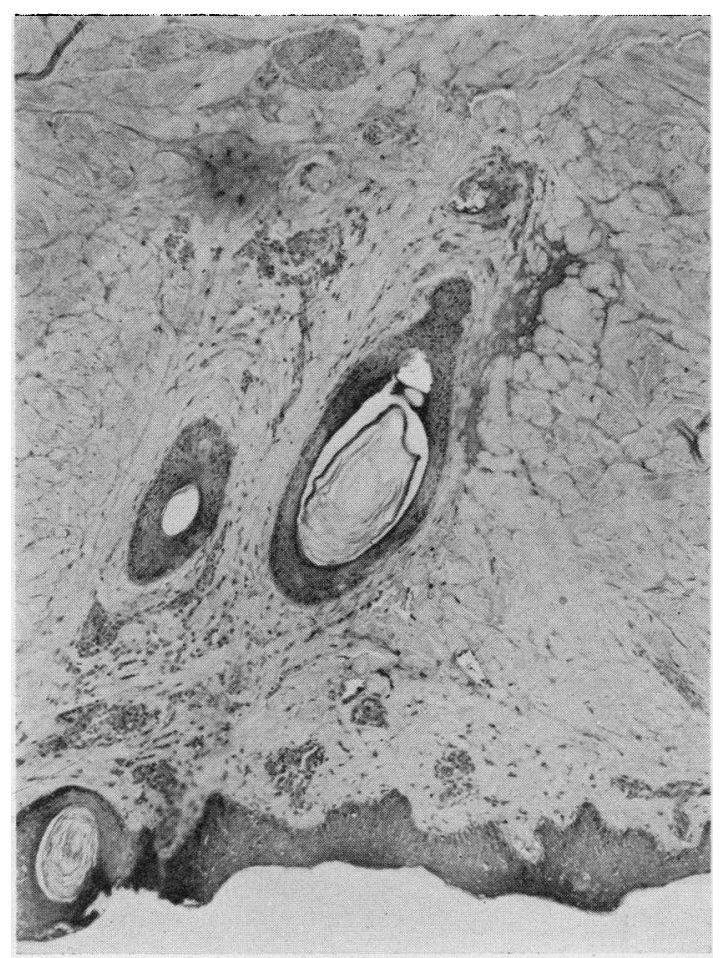

Fig. 2. Cutaneous Eruption during Chronic Chloroquine Administration

Photomicrograph of biopsy specimen in Case 1. Scattered lymphocytic infiltrates in the subpapillary layer and in the mid-corium. the last dose of chloroquine and continued to fade until, in five weeks, only macules of pigmentation with slight central depigmentation remained. Some of the macules showed slight wrinkling of the surface.

Biopsy of a typical lesion showed on microscopic examination (Figure 2) slight hyperkeratosis, but an otherwise normal pigmented epidermis. There was a dense perivascular lymphocytic infiltrate around the vessels of

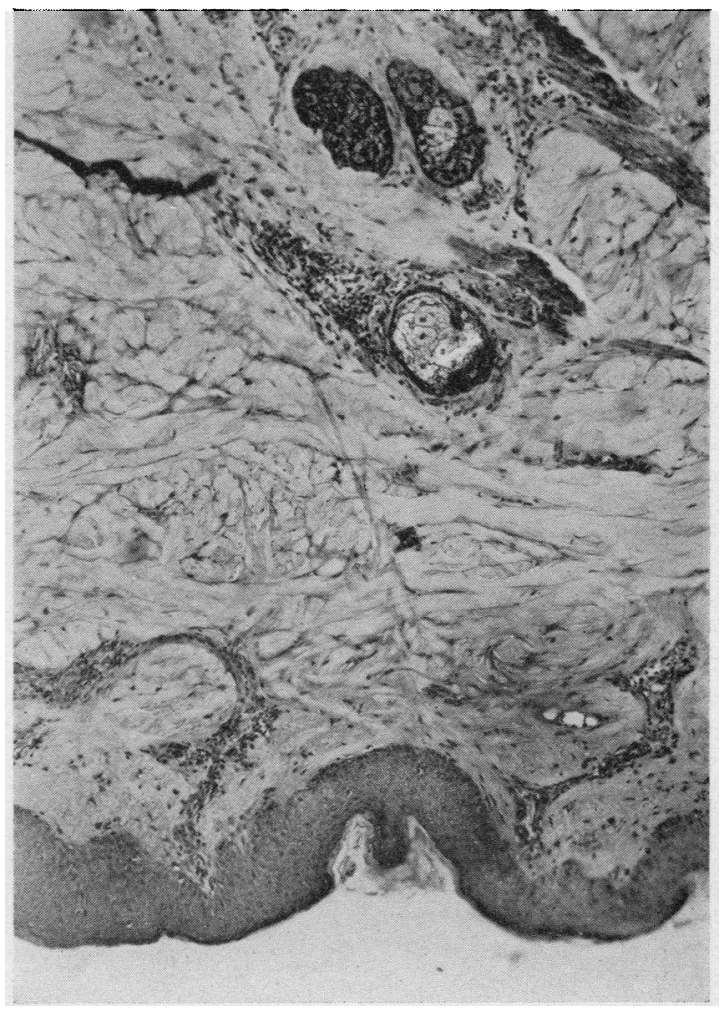

Fig. 3. Cutaneous Eruption during Chronic Chloroquine Administration

Photomicrograph of biopsy specimen in Case 2. Perivascular and periglandular round cell infiltration. 
the subpapillary venous plexus. The microscopic appearance was that of mild chronic dermatitis.

Case 2: A 25-year-old healthy white male complained of $\mathrm{n} n$ symptoms during the year of chloroquine administration except occasional headaches, often occurring six to 12 hours after the weekly dose of the drug and, on several occasions, of a transient urticaria.

In the 12th month of chloroquine administration, a macular eruption appeared on the flexor surfaces of both arms. The macules were vivid red to faint yellowish red, the color completely fading on pressure under glass. No palpable lesions developed from the macules. They were not pathognomic of any skin disease and disappeared within six weeks after the drug was discontinued.

A biopsy of one of the lesions showed slight hyperkeratosis but an otherwise normal epidermis. There was a scattered lymphocytic infiltrate in the papillae, which were markedly edematous. In the subpapillary layer there was dense infiltration around the vessels of the subpapillary venous plexus. In one area in the lower corium there was a dense lymphocytic infiltrate around a sebaceous gland. The microscopic appearance (Figure 3) was reminiscent of that of lichen planus and similar to that of the eruption following quinacrine administration.

\section{DISCUSSION}

Two men who received 0.5 gram of chloroquine weekly for one year developed lichenoid skin eruptions. It may be only a coincidence that both of the individuals had evidence of other cutaneous disorders, namely, neurodermatitis in Case 1 and urticaria in Case 2. In Case 1, the eruption appeared in the eighth month as a macular rash and slowly developed into an infiltrated eruption; in Case 2, the macular eruption appeared only in the last month of chloroquine administration. Since in both instances the rash rapidly subsided after the drug was discontinued, it is possible that in Case 2 the eruption was aborted after the macular stage and might have progressed to palpable infiltration and desquamation like Case 1, had chloroquine been continued longer.

The eruption in Case 1 was definitely lichenoid, yet not a single lesion showed the characteristic polygonal shape or the Wickham striae seen in lichen planus papules. The microscopic appearance of the biopsy section in Case 1 was that of mild chronic inflammation. Yet in Case 2, although the clinical eruption did not resemble lichen planus, the microscopic appearance did. It should be emphasized that the clinical course in both cases was mild, subjective symptoms were minimal, constitutional symptoms absent, and the eruptions faded promptly when drug was discontinued.
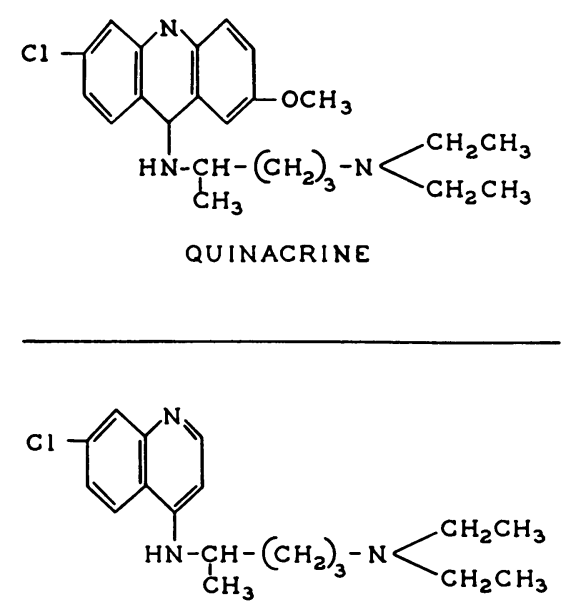

CHLOROQUINE

Fig. 4. Structural Formulae of Quinacrine (Atabrine) and Chloroquine, Showing Similarity of Configuration

A lichen-planus-like eruption not infrequently complicated quinacrine (atabrine) administration to troops overseas $(5,6,7,8,9)$. Individuals with lichen-planus-like eruptions due to quinacrine have been successfully treated for malaria with chloroquine without causing exacerbation of their skin lesions (3). However, one instance of exacerbation of a quinacrine-induced dermatitis upon the administration of chloroquine has been observed (10).

The development of a lichen-planus-like eruption as a toxic manifestation of chronic chloroquine administration has not been previously described though the drug has been administered to more than 5,000 individuals (1). It may be irrelevant that our patients had higher dosage than that required for suppression, since in 20 men in the toxicity" study at Stateville who took 0.5 gram daily for 11 weeks, or seven times the suppressive dose, no cutaneous eruption was observed (4). The occurrence with chloroquine of a lichenplanus-like eruption similar to that seen with quinacrine is of interest because of similarities in their chemical structures (Figure 4).

\section{CONCLUSIONS}

Of 30 healthy volunteers who were given chloroquine for one year in a dosage in excess of that required for antimalarial suppression, two developed cutaneous eruptions simulating the rash oc- 
casionally caused by quinacrine. The patients had no serious systemic symptoms and the eruptions disappeared promptly when the drug was discontinued.

\section{ADDENDUM}

Three months after the end of chloroquine administration the drug was readministered to Case 1 at a dose of 0.3 gram a day for 17 days without reappearance of the eruption. Two months after the termination of the chronic toxicity study, Case 2 resumed taking chloroquine in a dose of 0.3 gram twice a week. No cutaneous eruption developed in six months' drug administration.

\section{BIBLIOGRAPHY}

1. Loeb, R. F., Clark, W. M., Coatney, G. R., Coggeshall, L. T., Dieuaide, F. R., Dochez, A. R., Hakansson, E. G., Marshall, E. K., Jr., Marvel, C. S., McCoy, O. R., Sapero, J. J., Sebrell, W. H., Shannon, J. A., and Carden, G. A., Jr., Activity of a new antimalarial agent, chloroquine ( $\mathrm{SN}$ 7618). Statement approved by the Board for Coordination of Malarial Studies. J. A. M. A., 1946, 30, 1069.

2. Pullman, T. N., Craige, B., Jr., Alving, A. S., Whorton, C. M., Jones, R., Jr., and Eichelberger, L.,
Comparison of chloroquine, quinacrine (atabrine) and quinine in the treatment of acute attacks of sporozoite-induced vivax malaria (Chesson strain). J. Clin. Invest., 1948, 27, Suppl., 46.

3. Most, H., London, I. M., Kane, C., Lavietes, P. H., Schroeder, E. F., and Hayman, J. M., Jr., Chloroquine for treatment of vivax malaria. J. A. M. A., 1946, 131, 963.

4. Alving, A. S., Eichelberger, L., Craige, B., Jr., Jones, R., Jr., Whorton, C. M., and Pullman, T. N., Studies on the chronic toxicity of chloroquine (SN-7618). J. Clin. Invest., 1948, 27, Suppl., 60.

5. Livingood, C. S., and Dieuaide, F. R., Untoward reaction attributable to atabrine. Bull. U. S. Army Med. Dept., 1945, 4, 653, and J. A. M. A., 1945, 129, 1091.

6. Schmitt, C. L., Alpins, O., and Chambers, C., Clinical investigation of a new cutaneous entity. Arch. Dermat. \& Syph., 1945, 52, 226.

7. Nisbet, T. W., A new cutaneous syndrome occurring in New Guinea and adjacent islands. Preliminary report. Arch. Dermat. \& Syph., 1945, 52, 221.

8. Epstein, E., The lichen-planus-eczematoid dermatitis complex of the Southwest Pacific. Bull. U. S. Army Med. Dept., 1945, 4, 687.

9. Bereston, E. S., Lichenoid dermatitis. J. Invest. Dermat., 1946, 7, 69.

10. Report from the 20th General Hospital, India-Burma Theatre, to the Office of the Surgeon General, U. S. Army. 